\title{
Optical and electro-optical laboratory practice for undergraduates
}

Yuri Parvulyusov, W Ilyuhin, Vladimir Solomatin, Yuri Yakushenkov

Yuri B. Parvulyusov, W llyuhin, Vladimir A. Solomatin, Yuri G. Yakushenkov, "Optical and electro-optical laboratory practice for undergraduates," Proc. SPIE 3190, Fifth International Topical Meeting on Education and Training in Optics, (8 December 1997); doi: 10.1117/12.294376

Event: Fifth International Topical Meeting on Education and Training in Optics, 1997, Delft, Netherlands 
Optical and electro-optical laboratory practice for undergraduates

\author{
Yuri B. Parvulyusov, Valeri A. Ilyuhin, Vladimir A. Solomatin, Yuri G. Yakushenkov \\ Moscow State University of Geodesy and Cartography ( MIIGAiK ) \\ MIIGAiK Optical Department, Gorokhovski by-str., 4, Moscow, 103064 Russia
}

\begin{abstract}
General principles of arranging laboratory practice for training undergraduates are considered. Connections between laboratory practical training and training in designer's skills are discussed. Specific equipment of MIIGAiK optical and electro-optical laboratories are described.
\end{abstract}

Keywords: practical training , laboratory set , optical and electro-optical devices

\title{
1. INTRODUCTION
}

Since 1930 , MIIGAiK Optical Department has been engaged in education and training in a wide range of applied optics and optical engineering areas. It would be reasonable to train opticians through a uniform curriculum for the first four years of studying with differentiation for the last one and half or two years. The Bachelor's curriculum is liked the first stage would-be engineer's curriculum. The uniformity allows undergraduate students to select their future way consciously - either to Master's Degree or to Engineer's Diploma - after 4th-year's training on a uniform optical and electro-optical base.

Undergraduates can choose as one of Masters' Programs ( "Applied Optics", "Electro-Optical Systems and Devices", and "Laser Systems and Technology"), as one of Engineer's Specializations ("Electro-Optical Devices", "Assembly and Adjusting of Optical Instruments", "Optical Devices for Geodesy and Photogrammetry", “ Optical System Design", "Optical Metrology"). Some courses in Masters' and Engineers' curriculums are analogous through their titles and contents partly. But there are more scientific research works in Masters' Programs and more design works in Engineers' Specializations.

To develop practical skills and habits to undergraduates is the perennial problem for all our programs. The standard equipment manufactured by industry is used at the first stage of training for studying general scientific and technical courses, for example, "Physics", "Applied Optics", "Electronics", et al. But for senior undergraduates' practice it is necessary to work out the special laboratory equipment as many industrial devices are unfit for training students because of methodical point of view. The nomenclature of optical and electro-optical devices ( OEOD ) increases constantly, and it makes arranging laboratory practice to be very relevant since undergraduates must be acquainted with the fundamental principles of OEOD construction and operation first of all. So it is very important to standardize laboratory equipment.

In the paper we consider some general principles of arranging laboratory practice for training in OEOD used at the MIIGAiK Optical Department. Then we discuss some forms of design undergraduates' training. Finally, a series of standardizied and unified laboratory sets worked out and manufactured at MIIGAiK are described briefly. These sets are used for different OEOD modeling. A modular principles of construction with elements and blocks which are easily replaced are a base of the sets.

\section{SOME GENERAL PRINCIPLES OF ARRANGING LABORATORY PRACTICE}

It is known that the major purposes of design and laboratory practice in higher school are the following:

- activization of the student's cognitive interest in the subject studied;

- overcoming the passivity while acquiring knowledge, and foremost while listening to lectures;

- deepening and consolidating theoretical knowledge through experiments;

- getting to know various equipment and instruments as well as ways and methods of their usage in solving specific practical problems. 
Practical work should contribute to the development of the student's self-dependence and creative initiative, it is one of the most active classes, and finally, its role is especially great in teaching professional skills and habits.

Besides, laboratory practice shows advantages of experimental methods of solving some important problems. E.g., experimental ways of determining optical transfer functions in complex optical systems are far simpler than analytical ones, and it may be illustrated in laboratory practice.

In practice, there exists a tendency to "accumulate" with years more and more kinds of laboratory and design problems in many courses. This accumulation is at variance with the limited number of hours that are allocated to this or that course by the curriculum which is rather conservative, i.g. it changes slowly enough. Both an introduction of a new course with some practical works to support it and a constant modernization of existing one need to develop general methodological criteria and approaches to forming laboratory and practical- design works.

We can consider the following as rather general purposes of practical work in higher school :

1. - better mastering and consolidating of the lecture material;

2. - acquainting a student with some specific theory problems;

3. - stimulating a student to study independently some course parts;

4. - acquainting a student with the experimental methods, developing his skills and habits in research work;

5. - acquainting a student with modern complex equipment;

6. - developing practical professional skills;

7. - solving through experiments some important particular problems.

The purposes of practical training and priorities of these purposes can be different at various stages of student's teaching and for different courses. Besides, there may be changes in priority of the purposes while there is a switch to both the speciality general technical subjects and narrowly-specialized ones. Thus, proving the main theoretical theses in experimental ways is of less importance in senior years. As, for example, it is hardly necessary to prove to a student the possibility of describing the nature of optical emission both discrete (photon) and continuous (wave) forms, or to verify any other fundamentals of optics. It is more important to teach a student to determine if the level of adequacy is enough in practical applications of optical phenomena models.

At the stage of specialization, students carry out laboratory practice which do not illustrate only the lecture material, as it was in the case when they have studied the natural-scientific and general engineering courses. In order words, laboratory practice looses its passive character. For example, laboratory practice on interference within "Physics" or "Physical Optics" courses is, as a rule, qualitative character, but within the frames of "Optical Measurements" the purpose of the same laboratory work may be to get quantitative dependencies of describing this phenomenon and its application to metrology.

The order of priorities of the above purposes on the list may be different. Thus, the first three, showing the desire to activize the student's cognitive activity, are of greater influence while teaching fundamental ( natural-scientific ) and general engineering subjects of the student's speciality, such as "Geometrical Optics", "Theory and Design of Electro-Optical Devises"; but purposes 3 - 6 are of great influence to the subjects "Optical Measurements" and "Optical Sources and Detectors". Priorities do change when students start to learn subjects of their specialization. From this point of view, then, purposes 4 - 7 have a great effect. But if the student's training be considered as a whole, then purpose 3 is of importance throughout its every stage. 
To streamline the arrangement of laboratory practice we think it useful to compile and analyze two kinds of tables:

- a chart of purpose priorities of practical work while teaching various parts of a subject ( Table 1 );

- a chart of purpose priorities of the particular types of laboratory works or design problems ( Table 2 ).

Table 1 is the most useful for arranging new courses and supporting laboratory practice. Table 2 makes it possible to classify both the already-accumulated or existing and newly arranged kinds of laboratory practice. The tables compare the priorities of the whole course or only priorities those of the laboratory practice with the existing possibilities. In order words, they tell the gaps in the laboratory practice.

These charts are useful for unfication of some available courses and supporting laboratory practice in the united ones. Simultaneous analysis of the both tables helps to arrange rationally the time table of the lectures and laboratory practice as well as to see the support of the lecture course by laboratory practice. It follows from our experience that compiling and analyzing these charts are very useful for working out of one and the same methodical approach to conducting a particular course by various teachers.

For example, below you can see charts ( Tables 1 and 2 ) for the course "Theory and Design of ElectroOptical Devices". Though the general structure of the course has been formed long ago and is practically the same in different higher school's programs and text books, the course itself and especially laboratory practice to support it are constantly being updated.

In the Tables the purpose numbers correspond to the above given on the list, i.e. 1 shows a better mastering and consolidating of the lecture material, " 2 " shows acquainting students with some specific theory problems, and so on. The sign " + " indicates various priorities ( Table 1 ) and a coincidence between a particular laboratory work or design problem and the purpose of the whole practice ( Table 2 ). These priority marks were received from 5 teachers of the MIIGAiK Optical Department.

To sum up the above mentioned, we would like to offer the following sequence of arranging a new or updating an existing laboratory practice:

1. to clarify the nature of the course as a whole and its priority purposes;

2. to compile a new and analyze the existing course program in order to determine general purposes of the practice (for the whole course) and priority purposes of each course part ( Table 1 );

3. to draw up a chart of purposes ( Table 2 ) to arrange it and to see if there is correspondence between Tables 1 and 2;

4. to prepare new kinds of laboratory and design-and-graphical works in order to provide the main priorities of the practical work for each course part;

5. to make up a calendar plan for the whole laboratory practice.

\section{LABORATORY PRACTICAL TRAINING AND TRAINING IN DESIGNER'S SKILLS}

Practical training in design courses ("Topics in Design", "Design of Optical and Electro-Optical Devices", "Assembly and Adjusting of Optical Instruments", and others ) includes a number of calculation and design works. Often these works are the beginning of laboratory set manufacturing .

At the first stage, laboratory and design practical training includes studying the different properties of typical mechanical, optical and electronic components and their working out (for example, cogwheels, screw mechanisms, lenses, optical condensers, modulators, optical radiators and detectors, and etc.). Besides, a student works out their mounting. Parameters and characteristics of the typical components are researched during the laboratory practical training.

At the next stage, a student develops the more complex units ( objective lens, scanning unit, optical analyzer, and etc.). At last the simplest OEOD is worked out. The logical completion of the laboratory and 
design practical training is a design of the typical OEOD, that is the term or diploma papers and projects developing.

\section{SOME EXAMPLES OF LABORATORY SETS}

At our senior undergraduates' laboratories, there are both scientific equipment manufactured by industry ( microcomputers, microscopes, autocollimators, aerophotographic apparatus, and etc.) and a series of laboratory sets have been worked out and manufactured at the MIIGAiK Optical Department. Our methodical approaches and designs have allowed to simplify and unify these training sets and to use a modular construction with blocks which are easily replaced and adjusted. Descriptions and instructions of our sets are very simple and don't occupy the main part of operaiting manual. Unified optical and electronic schemes should be applied for a number of courses training. The sets may be used for scientific research experiments and the new optical and electro-optical devices modeling.

The first set is the Microoptical Bench (MOB). This is compact, portable, easily used equipment. The MOB is a modul construction and allows to apply a small quantity of mechanical and optical components which are easily assembled, adjusted, and replaced. The MOB should be applied for demonstration in studying of such courses as "Physics", "Physical Optics", "Applied Optics", etc. Modernization or assembling a new laboratory work are possible without total dismantling the scheme to have been assembling earlier.

The Unified Adjustment Set (UAS ) enables to model the OEOD which have middle and large dimensions. As the MOB, there were modularity, manufacturing simplicity, not large cost as the major its figures of merit. The UAS is fully based on native elements. The list of the UAS components and units has been formed after analysis of many typical OEOD constructive shemes. Its major units are typical optical component mounts, illuminator units, optical detector and typical electromechanical component mounts, scales, and scale reading units. As examples of UAS using, it may be named the next UAS models:

- "The Set for Analyzer Parameter Investigations",

- "The Set for Lens Optical Transfer Function Determination",

- "The Set for Code Sensor Inivestigations", and etc.

Typical electronic blocks of electro-optical devices are modeling by the set named "Standardized Electronic Curcuits (SEC)". It is a set of such electronics blocks as photodetector switching on schemes, analog and digital filters, modulators and demodulators, digitizers, analog and digital multiplexers, time delay and integration units, and etc. Every block may be studied both individual circuit and combination with others. For example, the next laboratory works are carried out by means of SEC and focal plane arrays (FPA):

- "Principles of Interface Forming for Modern FPA",

- "FPA as Spatial Filter",

- "Time Delay and Integration at FPA Circuits",

- "FPA as Scan System",

- "Interpolation in Electro-Optical Transducers", and etc.

\section{CONCLUSION}

In this paper we have reviewed some general methods of arranging laboratory practice for training undergraduates used at MIIGAiK Optical Department. Based on our experience, we recommend to use special tables for optical practice forming. It is useful to exploit special modular unified equipment or laboratory sets for would-be opticians' training. 
Table 1. Purpose priorities of practical work while teaching various parts of a subject "Theory and Design of Electro-Optical Devices"

\begin{tabular}{|c|c|c|c|c|c|c|c|}
\hline Parts of subject & 1 & 2 & 3 & 4 & 5 & 6 & 7 \\
\hline 1. Signals and Noises in EOD & +++ & + & & & & & \\
\hline $\begin{array}{l}\text { 2. Effect of the Transmission Medium on } \\
\text { Performance of EOD }\end{array}$ & + & & & + & & & \\
\hline 3. The Optical System of EOD & ++ & ++ & & + & + & & \\
\hline 4. Image Analyzers of EOD & & ++ & + & & + & & + \\
\hline 5. Scanning in EOD & + & + & & & & & \\
\hline $\begin{array}{l}\text { 6. Modulation and Demodulation of Signals } \\
\text { in EOD }\end{array}$ & ++ & + & ++ & & & + & \\
\hline 7. General Block Diagrams of EOD & + & & + & & & & \\
\hline 8. Signal Filtering in EOD & ++ & ++ & + & ++ & & ++ & + \\
\hline 9. Methods of Optical Detection & + & & + & & & & \\
\hline 10. Radiant Energy Calculations & ++ & + & & ++ & & & ++ \\
\hline 11. Accuracy Calculation in EOD Designing & + & + & + & ++ & & & ++ \\
\hline
\end{tabular}


Table 2. Main purposes of some design problems (d.p.) and laboratory works (l.w.) of the subject "Theory and Design of Electro-Optical Devices"

\begin{tabular}{|c|c|c|c|c|c|c|c|}
\hline Design problem or laboratory work & 1 & 2 & 3 & 4 & 5 & 6 & 7 \\
\hline Determinate Signal Spectral Analyzing (d.p.) & ++ & + & + & & & & \\
\hline Graphical Convolution of Determinate Signals (d.p.) & & & & + & & & \\
\hline Signal Fourier-Synthesis (i.w.) & + & & & & + & & \\
\hline Signal Fourier-Analysis (1.w.) & + & + & & & + & & \\
\hline Photoelectric Impulse Analysis (l.w.) & + & ++ & & & + & & \\
\hline Fourier-Analysis in a Coherent Optical System (l.w.) & ++ & & & & + & & \\
\hline $\begin{array}{l}\text { Calculation of the Earth's Atmosphere Transmission } \\
\text { (d.p.) }\end{array}$ & ++ & & & + & & & + \\
\hline $\begin{array}{l}\text { The Graphical-and-Analytic Method of a Detector } \\
\text { Choise (d.p.) }\end{array}$ & + & & & ++ & & & ++ \\
\hline Electro-Optical Scanning (d.p.) & ++ & & + & + & & + & \\
\hline $\begin{array}{l}\text { The Image Analysis by the Focal Plane Array } \\
\text { Analyzer (d.p.) }\end{array}$ & + & + & & & & & + \\
\hline The Image Centroid Definition (d.p.) & & & + & & & & + \\
\hline $\begin{array}{l}\text { Signal Spectrum for the Reticle Modulator } \\
\text { Output (l.w.) }\end{array}$ & ++ & + & & & + & + & \\
\hline Synchronous Detection (1.w.) & ++ & ++ & & & & & \\
\hline
\end{tabular}

